\title{
Transforming the Object in Product Design
}

\begin{abstract}
Summary
Product design is a process in which multiple understandings of technology and society are transformed into characteristics of a product, into skills found in the design team, and finally, into scripts that prefigure the use of the technology. Because of its particular concern with mutual transformations of objects, social collectives and subjects, activity theory seems a potentially powerful framework for analyzing the complexity of product design work. I utilize the concepts of motive and object of activity to analyze an innovation process in a small high-tech company. This analysis shows that engagement with the novel objects in the design process led to a significant transformation in the expertise, organization of work and dominant motive of the work community. In theoretical terms, the analysis suggests an alternative to the idea that an activity has one objectified motive which is instantiated in an object in the material world. It may be sensible to analyze product design as poly-motivated and its motives as instantiated in a number of different project-objects.
\end{abstract}

\section{Introduction: Product design and development as transformative work}

Product design and development have aroused increasing interests in a number of interesting fields of research. The reason why science and technology studies as well as the management and product develop- ment literature have shown increasing interest in design work is largely the same: Design and product development work forms a focal point where social and technical issues are negotiated and inscribed into the emerging artifacts. While the management literature stresses the potential for knowledge creation in the multidisciplinary process of design (Zaff, 1993; Fleck, 1994; Leonard-Barton, 1995; Carlisle and Dean, 1999), the sociology of technology has emphasized the "politics" involved in and conveyed through the construction of new technology (Law, 1991; Bijker and Law, 1992; Rip, Misa et al., 1995; Williams and Edge, 1996). Nevertheless, both fields share the same reason for stressing the importance of design work. Product design is the process in which multiple understandings of technology and society are transformed into characteristics of a product, into skills found in the design team, and finally, into scripts governing the way in which the technology will shape the everyday life of its users.

Interest in studying product design as work is also due to the fact that it is a practice in which the importance of tools and of the social organization of work is accentuated in regard to the outcomes of the transformation process. However, the most estab- 
lished positions in the study of design seem rather partial and run counter to one another (Carlisle and Dean, 1999; Mutanen, 2002). The tradition of viewing design as a rational problem solving process starting from Herbert Simon's (Simon, 1996) work runs parallel to attempts to literally manage knowledge in design by pre-specifying the requirements that the design needs to meet (e.g. Ulrich and Eppinger, 1995). In contrast, the reflective practitioner model by Donald Schon stresses the intrinsic skills of the designer in the situational, reflective conversation with the material (Schon, 1983). While both of these views have insights about the complexity of design work, they are so far apart that the attempts to bridge them seem futile (e.g. Carlisle and Dean, 1999).

There is a need for theoretical conceptualizations of design work, that would be sensitive to the complexity, undefinability and situational character of design while accounting for the wider and more long-term processes and collaboration that play a part in design work. Especially, such a perspective should be sensitive to the co-construction of developed artifacts and to the expertise gained by the subjects (Mutanen, 2002). Issues regarding more long-term relations between the artifacts developed and the expertise created have been central to management studies, for example, in terms of corecompetences or core-capabilities (Prahaland, 1990; Leonard-Barton, 1995). However, management studies have not been much elaborated empirically and theoretically, and there is an obvious need for perspectives that allow for a more analytical description of the dynamic between the creation of the artifact and the work community. This perspective should also be able to incorporate the political and moral questions regarding the outcomes of the product design processes.

Activity theory seems a promising alternative for the theoretical understanding product design and development work. While activity theory is a theory about human conduct in general, its concepts seem particularly sensitive for understanding product design work. The theory attempts to conceptualize how imaginary and material resources are transformed into outcomes, for example artifacts, in a collaborative work activity. (Nardi, 1996; Miettinen, 1998; Engeström, 2000).

This paper particularly explores the activity theoretical concepts of motive and object in analyzing product design work. ${ }^{1} \mathrm{I}$ analyze the product development process of a wristheld safety-alarm, Wristcare, in a small Finnish high-tech company, IST ltd.. My discussion is based on a field study I conducted during the years 1999-2001. On the one hand, my data consist in interviews and observations of the product development in the company and of the use of their products. On the other hand, I used historical sources such as business and project descriptions which convey how the expectations and realisations of projects changed from year to year.

The structure of my analysis and argument in this article is as follows. In section 2, I introduce A.N.Leontjev's formulation of activity theory from the perspective of how artifacts and social collectives are linked to one another. I complement this view with two later re-conceptualizations of the notions of motive and object by Engeström and Miettinen. In relation to sections 3 and 4 we should note that the concepts of motive and object are meta-theoretical concepts in re-

\footnotetext{
1 The concept of object in activity theory originates from classical German philosophy and the notion of Gegenstand. It refers to an object within human activity which makes an object a material and at the same time conceptual entity laden with human motives and purposes (Engeström and Escalante, 1996, 361; Foot, 2002). From here on, I use the term object in this meaning.
} 
gard to design work. ${ }^{2} \mathrm{~A}$ common but naïve way to use them is to apply the concepts to an empirical material. This means that the concepts are treated as tools that are first operationalized for a particular empirical analysis, and then the analysis is conducted by using those tools. The reflection of the results is then supposed to tell how adequate the initial concepts were. But the lesson from history and anthropology is that while it is clear that concepts do guide researchers' empirical analysis, so do a multitude of other factors including the subjectivity of the researcher as a field worker and an analyst (Gadamer, 1975; Ankersmit and Kellner, 1995; Geertz, 1973). If we want to say something about the adequacy of the theoretical concepts, we must take a more mediated route. I start with an empirical analysis informed by my meta-theoretical pre-understanding of activity theory (section 3). From the data and researcher's theoretical understandings one can then generate intermediary concepts to create an analysis that does justice to the data (section 4.1). I move on to interpret this intermediary analysis with activity theoretical concepts (section 4.2.). Finally, I use this theoretical interpretation to see what kind of empirical conclusions it suggests (5.1), and as a basis for reflecting on and refining the initial meta-theoretical concepts (section 5.2).

\footnotetext{
2 Activity theory was originally developed in the context of psychology, particularly developmental psychology (Leontjev, 1978, 1981). When used in the context of collective work such as product development, it serves as a grand theory of human activity in general. It does not contain a theory about design work as such, but provides a (meta-theoretical) sensitivity of what such a theory should include.
}

\section{A critical introduction to the concepts of object and motive in the cultural histo- rical theory of activity}

\subsection{An introduction to the concept of object of activity in the work of A.N. Leontjev and its intellectual background}

In activity theory the concept of object stems from the dialectics of Hegel and its later interpretation by Marx. This intellectual heritage is essentially twofold. First, dialectics attempts to find a way in between two prevailing metaphysical stances, namely naïve empiricism, according to which we perceive nature directly, and the idealist position that we do not truly possess knowledge of material reality. Surpassing Kant's position that we possess inherent, unchanging categories and that only through those do we reach the reality of the world, Hegel posits that the relationship between humans and nature has an evolving character. Categories are not unchanging but develop in the course of the history of mankind leading to a fuller appreciation of the material and social reality. (Hegel, 1970, §178-196; Ilyenkow, 1977; for introductory notes see Beiser, 1999; Houlgate, 1999).

This stance leads to a second important position on the relation between human beings and the material reality. The material reality, the object, is seen as a means for the constitution and subsistence of human beings and not just a philosophical question of perception. Human beings relate to nature as cultural, idealized objects incorporating meanings of human conduct and social organization (Hegel, 1970, §178-196; Marx, 1984). The characteristics we have not yet apprehended are, nevertheless, regarded in relation to the ways we have already created 
cultural meanings. Human beings only develop qualitatively new ways of relating to the world by engaging in a conduct that transforms nature to meet human needs. This conduct, praxis, has a twofold importance since it refines both the object under transformation and the subject who is doing the transformative work and has to go beyond him- or herself in exploring new ways of transforming nature (Marx and Engels, 1959, 137-146; Hegel, 1970, §190-196; Marx, 1984). This philosophical heritage has had an important influence on the development of Vygotsky's cultural-historical psychology and on Leontjev's treatment of the object as a psychological concept.

In activity theoretical interpretations of Vygotsky's work, human conduct is seen as directed towards a material or ideal object, reached via the mediational means of tools and signs (cf. Leontjev, 1978; Vygotsky, 1978; 1989). This principle of mediation clarifies how cultural meanings become part of individuals' psychological development (Vygotsky, 1989). Regardless of whether Leontjev's theory is seen as continuing Vygotskys's work or as a separate theory (Kozulin, 1990, 239-277; Engeström, Miettinen et al., 1999), it is clear that Leontjev (re)formulates the concept of object in a novel way. This formulation occurs in the context of the relationship between human needs, motives and outcomes. In his analysis, the object is that which connects these components of activity. He points out that an undirected need state is not able to motivate human action. Needs must become motives directed towards imaginary or material objects which then become true bearers of the need, that is, something which is able to relieve the original need (Leontjev, 1978, 6264). Leontjev stresses how the genuinely human conduct is distributed among the participants in collaboration, thus reviving old
German ideas of Hegel and Marx about a material and direct, social mediation of material human activity. In terms of human psychology and action this means that individual goals, e.g. chasing game, become meaningful only as part of the whole collective activity of hunting with a social division of labor according to which some chase while others ambush the frightened game, thus, producing by their joint action and operations a materialized object, killed animals which relieve the participants' need-states of hunger and cold (Leontjev, 1981, 212). In other words, the object of activity is the true bearer of its motive in a sense that only the object can fulfill or relieve the need behind the motive. It connects the actions of the various participants under the same motivating whole and creates an object-oriented horizon that is transformed in the course of the activity (Leontjev, 1978, 62-65, cf. 76-78).

\subsection{Beyond key problems in Leontjev's view of the object of activity}

Leontjev's model highlights how the psychological processes of motive formation and action extend into the social settings surrounding the individuals and points to the mutual dependency between motives and objects. Nonetheless, later activity theoretical studies point out two shortcomings in this model in their analysis of the complexity of modern collective work, particularly in settings such as scientific research and product development.

The first shortcoming has to do with the treatment of the relationship between needs and outcomes. Having examined the psychological implications of the transition from animal to genuinely human societal activity, Leontjev seems content with an essentially unchanging human nature, a "human-animal", so to speak. When dealing with more 
complex societies, Leontjev drops the parlance of needs, motives and objects altogether and shifts into speaking about senses and meanings implying that the same basic structure of activity still prevails, only now in a more complex environment (Leontjev, 1978, $85-95,1981,222-259)$. This view neglects the complexity of exchange and mediation in modern societies characterized by relations of exchange-value.

Although Leontjev's hunting example is primarily meant to illustrate the animal-human transition (Kaptelinin, 2001, personal communication) a modern case of how hunger is converted into collective activity is illustrative. When I have a need for food, my goals include walking to the store and heating the pizza in the microwave, as well as doing some research and writing. These actions seem absurd if not looked at in the context of collective activity. But this time the activity includes thousands of people working in research, technology production, agriculture, food-industry, transportation, retail, etc. Fulfilling my need and turning the object of my motive into an edible outcome have come to comprise a gigantic labor conducted in a number of distinct areas of industrial society plus their complex mediations (cf. Silvonen, 1988). Leontjev's study of the disparity between the societal meaning and personal sense of individual action (Leontjev, 1978, 85-95), seems too restricted to do justice to activities in modern societies (cf. Kozulin, 1990, 252).

In the activity theoretical literature we see a shift over the years in the concepts of need and object in order to become better able to account for supra-individual phenomena. Kaptelinin locates the expansion from an individual to a collective subject of activity (and thus to a different concept of activity) to work by Petrovski in the 1980's and particularly to the work of Engeström (Kaptelinin, 1996, 57). In my interpretation, in Engeström's model of the activity system we find an implicit assumption about collective needs that motivate (local) collective activity systems that seek to fulfill societally recognized outcomes. These outcomes are then exchanged with other local activities which bring back resources for consumption etc. (Engeström, 1987, 73-91). A further implication is that Leontjev's explanation for the necessary objectivity of action: the fullfillment of individuals' needs, is now replaced by an objectivity required by transactions of exchange-value (Engeström, 1990b, 108) and by collectively shared motives and the self-motivating power of participating in specialized activities (cf. Engeström and Escalante, 1996).

Another aspect left underdeveloped in Leontjev's theoretical work is how the motive and object of activity are transformed during the course of activity. He does provide a clear account of how the motive is mediated in the transformation of material reality. The motive is only realized in the form of goals and actions fulfilling the goals. Nothing else is left of the motive than what is acted out in actions (Leontjev, 1978, 6365). Actions have two aspects: an intentional aspect, the anticipation of its course and outcome, and an operational aspect directed towards realizing the action under certain local circumstances by means of embodied motor operations (Leontjev, 1978, 65). Human beings are only in contact with tools and objects at the level of operations where they encounter the resistance of things. Following Hegel, Leontjev points out that we only 
know our goals fully after we acted (Leontjev, 1978, 65). ${ }^{3}$ In this way, Leontjev lays out the two aspects of object-orientation: the object-relatedness of action and that motives and imaginations are necessarily directed towards an external reality. However, while outlining how motives are played out as operations accomodated to a material reality, Leontjev does not provide a clear model of how changes in the operational aspect of action adjust the intentional aspect of action and, furthermore, how a changing intentional aspect of action transforms the collective motive animating the activity. ${ }^{4}$ Activity theory attempts to be a meta-theory for all human action and cognition. While the above shortcoming may not be a serious weakness in actions and activities with a more or less routine manner of execution, it amounts to a lack of sensitivity in regard to e.g. research and design where the execution and outcome of action is constantly uncertain. Studies by Miettinen and Saari show how the resistance of material conditions in scientific research

3 Leontjev's distinction between two moments of action holds a remarkable insight. Interpreted in Anglo-American philosophical vocabulary, Leontjev's model means that the intentional aspect is an ideal that only comes in contact with the world when turned into operations, particulars in contact with material reality, objects. The dialectics of ideality and particularity of action is central to the mediation of human action. The intentional aspect is fundamental to the structure of individual action where one must initiate a general anticipated action before one can even in principle know its concrete unfolding. As importantly, this dialectic forms a necessary precondition for joint action in which participants must anticipate others' action before it is fully unfolded in order to synchronize their efforts in a joint accomplishment. Action has to achieve a degree of meaningfulness before it is fully played out (Cf. Norros, forthcoming; Engeström, 1995).

4 Rather general notions are given in Leontjev (1978, 66-67) where he notes how actions may grow into activities and, on the other hand, lose the motive that initiated them, or shift their motive. causes experiments, projects, and gradually the whole activity to change direction and bring its general motive under significant (re-)negotiation (cf. Miettinen, 1996, 1998; Saari and Miettinen, 2001). They describe the "dual object" of scientific research by which they mean that the object of research is, on the one hand, to generate scientific expertise and, on the other hand, to create applications that respond to societal purposes. In doing so, they introduce a concept of "application object" which I see as an intermediary category between the experiments (actions) and the object of research (object of activity).

Understood in this way, the object of activity unites the horizons of expectation and the materiality and resistance of the things on which the expectations are realized and redefined into some outcomes. In this process, the goals and the true collective motive, the object of activity, are simultaneously evolving, instead of being fixed, predetermined or predetermining. To summarize, my interpretation of the concept of object differs from Leontjev's influential scheme by regarding individual needs as mediated by collective or societal needs instantiated in local collectives. Moreover, I regard the object of activity as evolving and changing in the course of the activity precisely because of its very materiality. This conception of object seems promising for coming to understand the multifaceted, contradictory and transitory nature of a technological project constructing artifacts as well as a community of practitioners. It holds promises of transcending the limitations of rationalized views of human action such as Simon's rational planning model or of subjectivistic stances such as Schön's reflective practice model. 


\section{The trajectory of the Wristcare innovation and product development work in the IST company}

\subsection{An Introduction to the Wristcare technology}

Now we move to the outline of the empirical material. My unit of analysis is the product development work in a community of practitioners which led to the formation of a small high-tech company International Security Technology Ltd (IST) that developed an innovative new product, Wristcare. The community of participants has been relatively stable over the years and gone through a suc- cession of projects and companies ever since the early 1980's. Their key innovation, Wristcare, is a new generation safety phone with sensors that continuously monitor the health of the user. It makes an automatic alarm in case it detects a severe disruption in the user's condition. Other aspects of the device are like those a traditional safety phone: It has an alarm button, and all alarms, automatic and manual, are mediated by a receiver unit and telephone network to a predestined end: to relatives, to an alarm center, or the nurse on call. This person then decides the appropriate action; for instance, calling the user, her neighbors, the maintenance or an ambulance (See fig 1). The use of the device is thus based on transmitting the alarm in the network of care.

Figure 1. The Wristcare-system and the Wrist-device ${ }^{5}$
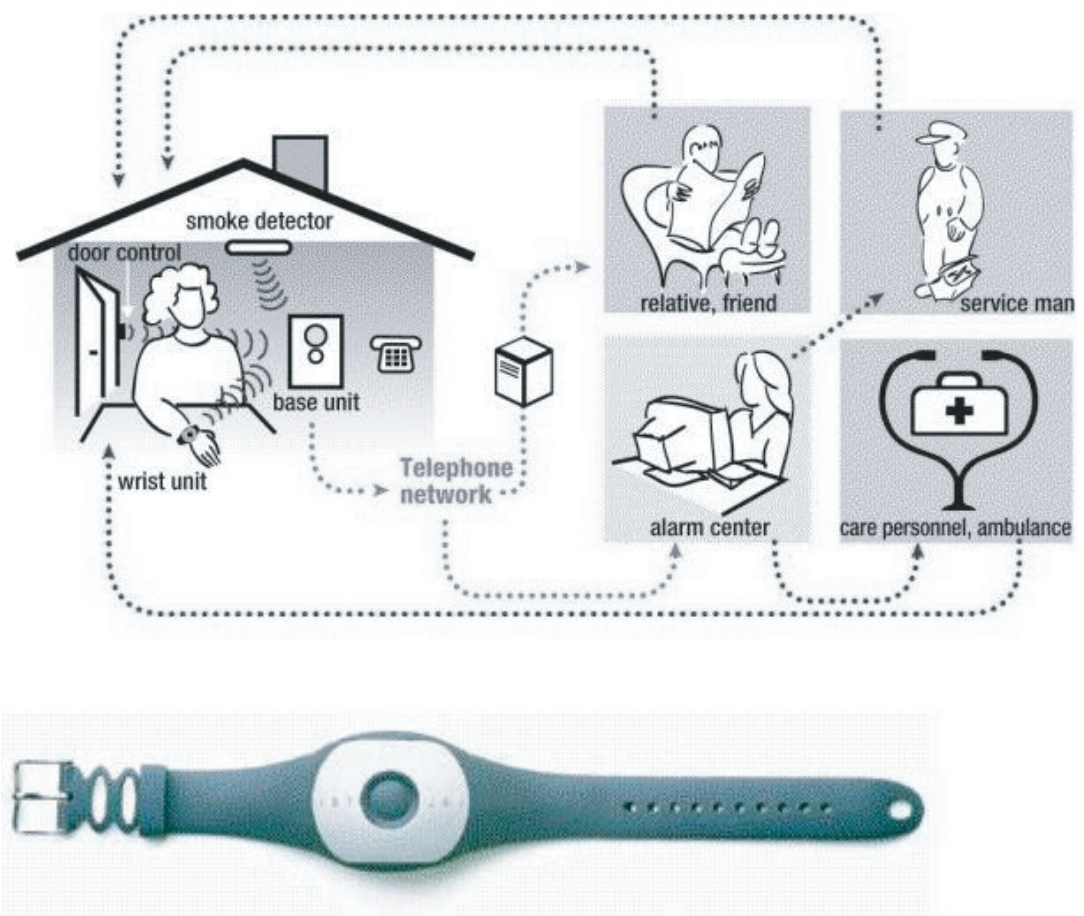

5 The pictures shown are company marketing materials. 


\subsection{The background of the Wristcare invention: $R \& D$ in Nokia and Sostel}

The company was based on its members' long experience with the development of traditional safety phones and signal transmission technologies. During the early 1980 s most of the later key-people in IST participated in creating signal transmission technologies in the Nokia corporation. Target solutions were in the area of residential healthcare (safety phones and remote electrocardiography) which was seen as growing market. In the late 1980s the key inventor in the later IST, Matti Myllymäki, founded his own company, Sostel ltd., which specialized in new solutions in residential security and health care (burglar alarms, robot phones, safety phones) based on signal transmission engineering. While the Nokia period was mostly research, Sostel went on to an early commercialization of these solutions. Myllymäki attracted some of his former colleagues from Nokia into his new company.

\subsection{Early IST in 1993-1995, creating new technical solutions}

IST Ltd. was based on the above mentioned business and technical experience in Nokia and Sostel, and Myllymäki sold the latter in the beginning of the 1990's. During its early years, IST consisted of 3-4 people who had already been collaborating in Nokia and Sostel. The initial thrust to found IST came from Myllymäki's early experiments with a concept for a new kind of safety phone, Wristcare. However, this ambitious productconcept was soon complemented by ideas for three less demanding products targeted for the security of the elderly and ailing people. The idea of additional products was to a large extent due to initial difficulties in convincing investors to fund the ambitious Wristcare project. The addition of comple- mentary products portrays the way the early IST worked: when the main product faced difficulties, the inventor and the engineers just went on to create other applications. In the early years, 1993-1996, the preliminary outcomes of their work were patents and prototypes related to all the four devices which were marketed for potential investors. The product-concepts, the Wristcare, the "Basic-alarm" burglar alarm device, the PillDispenser, and the electronic memo-calender, were all targeted for the safety of elderly people. The key idea was to make all the products "plug and play" aids which would compete against more complex, intrusive and expensive products. Consequently, the products were developed to be mass-produced and to stand-alone with few maintenance costs.

The Wristcare project dominated the research and development within IST. The concept was prompted by ideas from medical diagnostics, process automation and the existing "passivity sensors" in safety phones. ${ }^{6}$ Wristcare was seen as a crucial improvement over existing safety phones and their accessories (distributed sensors around the house or rest home) which many users considered to be clumsy. Likewise, the IST engineers regarded the existing phones as insufficient in cases where the person was unable to activate an alarm him- or herself, for example in cases of acute attacks of illness, accidents and dementia. The engineering work with Wristcare consisted mainly in working on the signal transmission, the de-

\footnotetext{
6 More precisely, the key idea is not to attempt to monitor the actual incident accurately, for instance a stroke. That would require a rather extensive and energy consuming technology. Instead, the idea is to monitor the effects created by an acute attack of illness, for instance a shockstate, which can be detected with a considerably cruder instrumentation and yet may well be sufficient to detect those instances where acute help is needed (For a detailed analysis of the invention phase, see Hyysalo, forthcoming b).
} 
tection of states of alarm and the construction of principles for the physical monitoring. The IST designers explored the available components, sensors etc. needed to realize the device and analyzed competing products. The reference users for Wristcare were $60+-y e a r$ olds, still relatively healthy elderly living in their homes. The business idea was to create a new market of still healthy elderly with a heightened risk of e.g. a coronary disease. The users were not actively consulted as for the design. They only served as a reference for how to construct the physiological monitoring.

The innovators believed that the users' actions and the organization of those actions will basically remain the same as with the older push-button safety phones with which the company already had experience. Some user interviews were conducted with potential customers and two market surveys were conducted on European markets. These studies attempted to specify how the new products were positioned in reference to competitors and user preferences, the appeal of the concept, the price, and so on. The infrastructure, the context of use, and who the users and buyers actually were, were addressed in rather vague terms: "the elderly and ailing people requiring heightened safety measures for their health" (Functional description of Wristcare, 1993). In 1995 IST commissioned a design study indicating that to focus only on the technical details of the wrist-device would be insufficient. However, tight funding prevented the company from making any major changes in their initial concept while there were strong indications for the need and potential market of the new technology.

In 1993 it was estimated that Wristcare would be marketed in the "near future", meaning 1995, but the development process took considerably longer and Wristcare was first piloted in the late 1997. During the years 1993-1997 "basic-alarm" evolved to a wireless, more all-encompassing "Multicontrol" device covering most of the standard burglar alarm features in one neat package. Some work had also been made with pill-dispenser while memo-calendar never saw daylight.

\subsection{Extending $R \& D$ from the devices to the augmentation of work in a net- work of care}

Wristcare was launched on the market in 1998. The pilot use was seen as a success in terms of the ambitious technology. However, it soon became apparent that more was needed than the wrist and receiver units in order to capitalize on the utility of the new system. Problems and suggestions became real, for the first time, as users explained and complained about their experiences with the device. In the years 1998-1999, the company took various measures to improve the deficiencies and malfunctionings. These included training and the development of tools for the care-providing network, especially the alarm-transmitting centers. It also became apparent that rest homes, diabetics, epileptics, the demented and elderly living in their homes had incommensurably different needs and capabilities for using the technology. Consequently, the product design, marketing and training took many simultaneous paths. In 1997 the company mission had changed from exploratory research and technical problem solving into that of a developer and manufacturer of an existing product (IST business plan, 1997). IST began to emphasize the whole technical system and care solution of Wristcare, instead of focusing narrowly on technical features of a singular piece of technology. The product and its advertisement were now not only oriented towards potential investors but also towards health-care professionals and potential purchasers. The flagship product, Wristcare, 
supplanted the other product-projects which were never produced in significant quantities. The Wristcare technology also defined the company's visions. Wrist-monitors were seen as devices for "well-being" that could also be used by younger people in dangerous jobs, by risk groups or by people otherwise concerned with their health. The safetyphone marke - in all its now perceived complexity - was also seen as a hindrance because safety phones were strongly associated with the very last years of life and had limited appeal to groups of younger users.

However, in 1997-1999 the company's funding was still tight, and there was still plenty of work to do with immediate improvements. Many projects seemed to take resources from each another, and the employees were uncertain of the company's priorities and of which directions should be taken.

\subsection{The redesign of products and the reorganization of the company during the years 2000-2001}

Following increased funding and technical problems in their current design, IST launched a design project for a new generation of Wristcare, its receiver unit and control software, in the years 1999-2001. These redesign projects aimed at integrating the various lines of development, suggestions for improvements, and local solutions which had made the technology work in various user-sites. The expressed aim was to create a device that could be produced in large numbers and sold widely internationally. This state, originally expected already in 1995 , was finally reached in the late 2001. Events in the company during 2000-2001 help us understand parts of this delay.

During the years 1999-2001, the company doubled its personnel. New CEO heads for marketing, product development and product management were hired from bigger companies that had already handled the transition to international markets. IST as a company, especially its research and product development, were more formally and systematically organized according to certain projects and schedules. The long-term visions of the company went through a year long process of re-definition assisted by external consultancies. The short-term goals were organized strictly around making the new generation of the core technology fully functioning and ready for the market. This meant concentrating work on the most urgent developments while freezing the many other projects that had arisen during the years 1997-1999.

Although a rapid internationalization had been the expressed aim of the company right from the start, the new personnel considered that in many respects the company had been working like a small domestic company especially in regard to product development. When internationalization found its way from an abstract vision into concrete action, it encountered a number of tensions with the prevailing activity: 1) in the designed product, 2) between old tools and new goals, 3) and between the new goals and the organization of the company.

The first tension lay in the designed product. While the internationalization demanded a reliable and well-documented technical layout, the wrist-unit was the result of almost ten years of combined gradual improvements and tinkering with the best available resources. It was hard to determine how configuration changes changed the functionality of the system. Second, the tools used to create Wristcare in the early 1990's were outdated in regard to the standards to be met in the year 2000. Since many key areas had to be reconfigured with more modern components and programs, the conversion from old to new tools burdened the construction work. The third tension was between the new ob- 
ject and the old way of working in the product development. The IST R\&D had mainly been research and continuous improvement. Though there was a widespread consensus to move to a more systematic product development with tighter standards, testing and scheduling, the old ways of working still prevailed. Under a tight schedule, the old research kind of approach, "just to make it work", proved to be the most effective shortterm strategy in dealing with the complex and interdependent configuration of the device. Fourth, as the unpredictability of technical outcomes continued, the prevailing tension between the R\&D and the marketing remained. Campaigns for marketing, getting pilot tests for government approvals as well as selling the device had to be postponed many times.

There are a number of interesting issues in the adjoined trajectories of the Wristcare and IST product development (outlined in fig. 2) that call for further explanation. First, why has the Wristcare innovation process taken so much more time than initially anticipated? This has been a nagging question for the IST inventors, something they feel they need to clarify often, especially to financiers. Second, why has it taken so long to accomplish the transition from engineering centered design to a more user-centered way of working? Third, why is a secure and reliable monitoring still a major issue to be considered even in the third, forthcoming generation of the device? And fourth, why has the 20002001 organizational transformation been such an effort? To answer these questions I move on to analyzing the changes in the work community of the IST during the innovation process.

\section{Understanding the dy- namics of product develop- ment by analyzing changes in the community of work}

\author{
4.1. The development of a technological \\ innovation in the context of required ex- \\ pertise
}

So far we examined the IST product development almost as if it was only a technical process. In the following, the analysis is taken further by connecting the changes in the technical development with changes in the community of practice during the innovation process. In the production of technology, the technical development is irredeemably intertwined with economical and social concerns, and any one of these parts can hardly be understood without the others (Hughes, 1983; Bazerman, 1998). When we consider product development as a socio-economicaltechnical activity, it becomes an immensely complicated issue. To make sense of this complexity, we must emphasize some aspects. First, I outline how the goals and expectations of the developers evolved during the process. Second, our analysis must focus on the development of expertise in the company since the products and the capability to develop them can hardly be separated, as emphasized in recent discussions about product development (Leonard-Barton, 1995).

In this section, I shall use a number of intermediary concepts to make sense of the complexity of the product development in IST, as a step towards analyzing the process with activity theoretical concepts. These intermediary concepts are only approximate and not very specified, my emphasis being that they remain empirically grounded. To make it easier to read the analysis, I describe those terms tentatively here. The first inter- 
mediary concept is the "product and business project". It originates from the members' category of project and refers to the fact that products are always projects for a $\mathrm{R} \& \mathrm{D}$ company and that R\&D and commercial aspects are tightly interconnected in such projects. The second intermediary term is the "application domain" which I use to describe the domains towards which the "product and business projects" have been directed. The members talk about the same issue as "engaging in the business of", e.g., safety phones. In their use, however, "business" covers the technical and commercial projects as well as the user-practices, the competition and the commercial logic in a techo-socialcommercial domain, thus, covering a lot more than is usually meant by business. With the term "application domain" I want to elaborate how the expertise in the company is not abstract but directed towards and shaped by participating in certain domains, or "businesses" to paraphrase the members' category. The third intermediary term is the "horizon of business and product opportunities" which refers to imagined, and in principle realizable, future products and projects. It is typical of technology production that only some of these ever become actual R \& $\mathrm{D}$ efforts while most remain concepts, papers and visions which, nonetheless, effect the directions the company takes in its $\mathrm{R} \&$ D. The final intermediary concept is the "required expertise" which refers to the expertise needed to complete a "product and business project" successfully in an "application domain". In my analysis I use this notion to highlight the expertise that is not readily available for the developers when they are engaging in a product and business project.

I start by summing up the changes in the "product and business projects" which the IST designers worked with during the period I analyzed. During the Nokia-Sostel period the later IST developers worked with a num- ber of different projects. In the first phase of the IST product development there were four projects of essentially "different technologies": a condition monitor, a burglar alarm, a pill dispenser and a memo calendar. What unified these projects was that all relied heavily on electronical and signal transmission engineering and had partially overlapping, targeted customers and environments of use. At the end of the period I analyzed, 2001, there was only a single application, Wristcare, which had some product variation for some of its potential user groups. From this I conclude that a kind of "funneling" occurred concerning how many "application domains" or "businesses" the company is engaged in.

Changes in the application domain are inseparable from the innovators" "horizon of business and product opportunities". In the Nokia-Sostel period these horizons concerned a broad range of possibilities residing in various signal transmission applications robot phones, burglar alarms, safety phones, alarm centers, and so on - broadly concerned with emergencies and message transmission. Even in the earliest documents of IST, Wristcare was seen as the application with by far the greatest business potential. Nevertheless, its realizability was uncertain, and the horizon of business and product opportunities also included considerations of other products. Likewise, possibilities existed for selling the rights to the Wristcare-concept or the whole company to a bigger company (Business Plan, 1995; interview with the company President, 21.05.2001). The 1997 market launch marked a dramatic change in the horizon of business and product opportunities. Support products were gradually dropped as the economically much more appealing Wristcare was now trusted to stand on its own feet. This was concretized in various visions, plans and design concepts for new applications based on the Wristcare con- 
cept. (Business plans, 1997, 1998; interview with the company President, 15.10. 1999, 21.05.2001). This transition was taken further by the possibilities arising from the monitoring function of Wristcare. In 1998 IST made a showcase graphical illustration of the "activity level" that Wristcare monitored. Users regarded the graph as highly valuable in clarifying their work with the devices. The company responded by developing this visualization further which in turn opened new possibilities. By the year 2001 the horizon of possible future products was well beyond the security devices for risk groups. Constant on-line body monitoring was seen to have a potential for a number of recreational, sports and rehabilitation applications under the theme of "technology for well-being".

What we see here (illustrated in fig 3) is an intertwined change. On the one hand, the horizon of potential future products and the business opportunities narrowed from multiple domains of application into a single domain: the potential solutions of Wristcare in various target markets and user groups. On the other hand, the future visions of the Wristcare technology moved beyond the domain of application of a personal security device.

Figure 2. The change in the IST product and business projects analyzed in terms of application domains with a "funnel" into a single domain, and the horizon of business and product opportunities where concentration into one domain opened significant new opportunities.
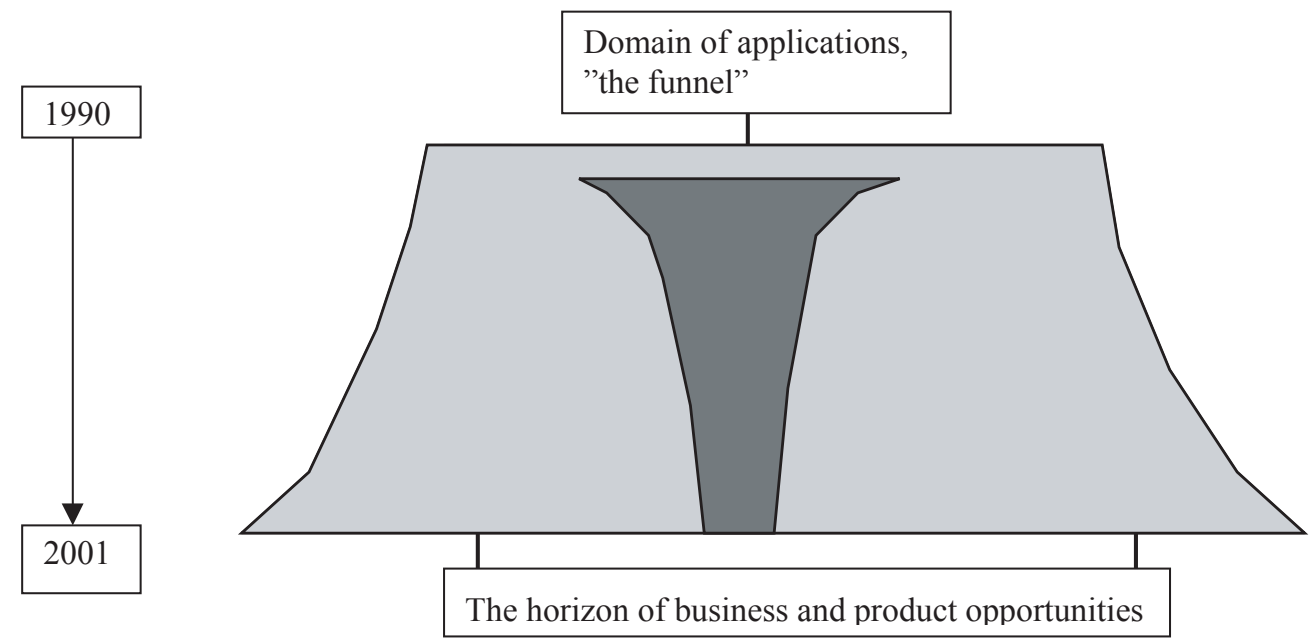

Having now outlined the most significant changes in the products and business projects and in the horizon of future products and business opportunities, I shall examine how these changes are connected to changes in the expertise in the company.

During the Nokia and Sostel period, the developed applications, safety phones and burglar alarms, as well as the expected future products, relied mainly on the expertise in the signal transmission engineering. Wristcare marked a rupture in the expertise needed in the product development in the community of practitioners. While the existing kinds of engineering knowledge were needed for Wristcare, it also increasingly required knowledge in physiological monitoring and technological expertise related to various 
sensors and data-modeling. This new knowledge was not readily possessed by the engineers. Still, in the period of 1993-1997 the novel ways of using existing expertise in signal transmission, e.g. combining the device with a cellular phone, occupied the most important place in the imagined future applications of Wristcare. In addition, there were still two other products beside Wristcare.

The second rupture in the required expertise of the developers emerged in 1997-1999. Upon completion of the Wristcare other projects were gradually dropped. At the same time, Wristcare faced a number of problems in the user practices. These problems partly concerned signal transmission expertise, but most problems were related to monitoring and to poor considerations of how the devices fitted into practices of use. IST was forced to create new solutions and improvements to Wristcare and its support infrastructure, such as monitoring programs. Despite these difficulties, Wristcare widened the designers' horizon for further product and business opportunities with the same core-technology. Again, as with the other ongoing projects, the horizons for future product and business opportunities were partly based on novel transmission solutions; e.g. combining a number of devices to form a system for sheltered housing and creating door-detectors for those suffering from dementia. At the same time, other applications such as the development of products for the special needs of epileptics and diabetics required improving and altering the monitoring functions (Business plan, 1997, 1998).

During 2000-2001 IST took further steps towards monitoring and user-friendliness.
The creation of "activity level" and "activemonitoring" wrist-devices and software since 1998 had important implications for the required expertise. By 2001 these features had developed further, and what the company now called "activity curve" became a core feature in comparisons of Wristcare with more established monitoring devices such as Polysomniography and Actiwatch. Previously, IST had not considered attempts at medical approvals to be within their reach, but these new paths in product development made that goal realistic. This promoted the company's engagement in physiological monitoring with the expertise it required and the business opportunities it provided. The development was accentuated by the horizon of business opportunities in niche products in technologies for well-being which further emphasized the competencies in monitoring and in understanding the targeted markets and user activities.

However, alongside the ever-rising expectations, the company's expertise faced a significant challenge in attempting to make the core technology sufficiently reliable and the organization able to bring the second generation device to the markets with already passed deadlines. From the perspective of the new personnel hired by the company, the developers' knowledge of signal transmission expertise had lagged behind the extremely rapid phase of development in other industries of signal transmission, in available components and programming languages. (interviews with the manager of $\mathrm{R} \& \mathrm{D}$, 14.11.2000; meeting observations in 2000). 
Figure 3. Summary of the development of the IST R \& D in terms of product and business projects and key expertise created and maintained

\begin{tabular}{|c|c|c|}
\hline $\begin{array}{l}\text { Phase of product } \\
\text { development }\end{array}$ & $\begin{array}{l}\text { Key expertise created } \\
\text { and mainained in }\end{array}$ & Product and business projects \\
\hline $\begin{array}{l}\text { Product design at } \\
\text { Nokia and Sostel } \\
\text { 1978-1992 } \\
\text { 3-10 engineers lead- } \\
\text { ing independent proj- } \\
\text { ects }\end{array}$ & $\begin{array}{l}\text { - Signal transmission } \\
\text { engineering, particu- } \\
\text { larly related to various } \\
\text { alarm system }\end{array}$ & $\begin{array}{l}\text { - Safety phones, robot phones, residential } \\
\text { alarm systems } \\
\text { - Patenting, marketing, and early commer- } \\
\text { cialization of products } \\
\text { - Selling the projects to investors and other } \\
\text { companies }\end{array}$ \\
\hline $\begin{array}{l}\text { Product design at } \\
\text { IST, 1993-1997 } \\
\text { 3-5 engineers doing } \\
\text { research on monitor- } \\
\text { ing and signal trans- } \\
\text { mission }\end{array}$ & $\begin{array}{l}\text { As in } 1980 \text { 's }+ \\
- \text { monitoring of physical } \\
\text { condition, sensors and } \\
\text { technics }\end{array}$ & $\begin{array}{l}\text { - Exploratory research and R \& D for four } \\
\text { products in different application domains } \\
\text { - Patenting and marketing to gain funding for } \\
\text { the concepts }\end{array}$ \\
\hline $\begin{array}{l}\text { Product design at } \\
\text { IST, 1997-1999 } \\
6-8 \text { engineers and } \\
\text { salespersons devel- } \\
\text { oping a new product }\end{array}$ & $\begin{array}{l}\text { As in 1993-1997 + } \\
\text { - Understanding and } \\
\text { designing for the envi- } \\
\text { ronment of the elderly } \\
\text { users }\end{array}$ & $\begin{array}{l}\text { - Development of Wristcare core technology } \\
\text { - Various measures to make the devices fit } \\
\text { user-practices. From devices to a functional } \\
\text { system } \\
\text { - Marketing and fundraising } \\
\text { - Marketing for end users and institutions }\end{array}$ \\
\hline $\begin{array}{l}\text { Product design at } \\
\text { IST, 1999-2001 } \\
\text { 10-15 engineers and } \\
\text { salespersons aiming } \\
\text { for international mar- } \\
\text { kets }\end{array}$ & $\begin{array}{l}\text { As in } 1997-1999+ \\
\text { - internationalization of } \\
\text { sales and heightened } \\
\text { technological standards }\end{array}$ & $\begin{array}{l}\text { - Creating a new generation of the Wristcare } \\
\text { system } \\
\text { - Meeting the reliability standards required of } \\
\text { big series and international markets } \\
\text { - international marketing and alliances } \\
\text { - Improving the research and development } \\
\text { processes inside the company }\end{array}$ \\
\hline
\end{tabular}

To sum up the developments (see fig. 4), in comparison with previous years, by the end of 2001 IST's products and targeted markets had narrowed down to the personal safety of the elderly with basically two versions of the Wristcare system. From the Nokia and Sostel period there has been a "funnel" in the "application domain" during the IST years. The previous wide range telecommunication know-how turned into a deeper but more restricted knowledge related to the particular product that integrated transmission and monitoring technologies. The horizon of business and product opportunities was changed, first from various signal alarm solutions to safety devices and then further to various applications of Wristcare in new ap- plication domains. Throughout this change process the scope of potential business and the amount of potential applications kept growing.

Most importantly, during this change in products, application domains and horizon of business and product opportunities, the required expertise went through two major qualitative transformations. The relative importance of expertise in signal transmission engineering declined dramatically compared with the required expertise in physiological monitoring and in the understanding of the use-contexts. This change was most profound in regard to the horizon of business and product opportunities. 
Figure 4 The development of the IST R \& D in terms of product and business projects, the horizon of business and product opportunities and the required expertise. We see a narrowing of application domains and of the relative importance of the original signal transmission expertise. There are two major ruptures in the required expertise imposed by the Wristcare product. Expanded future prospects depend on new acquired expertise.

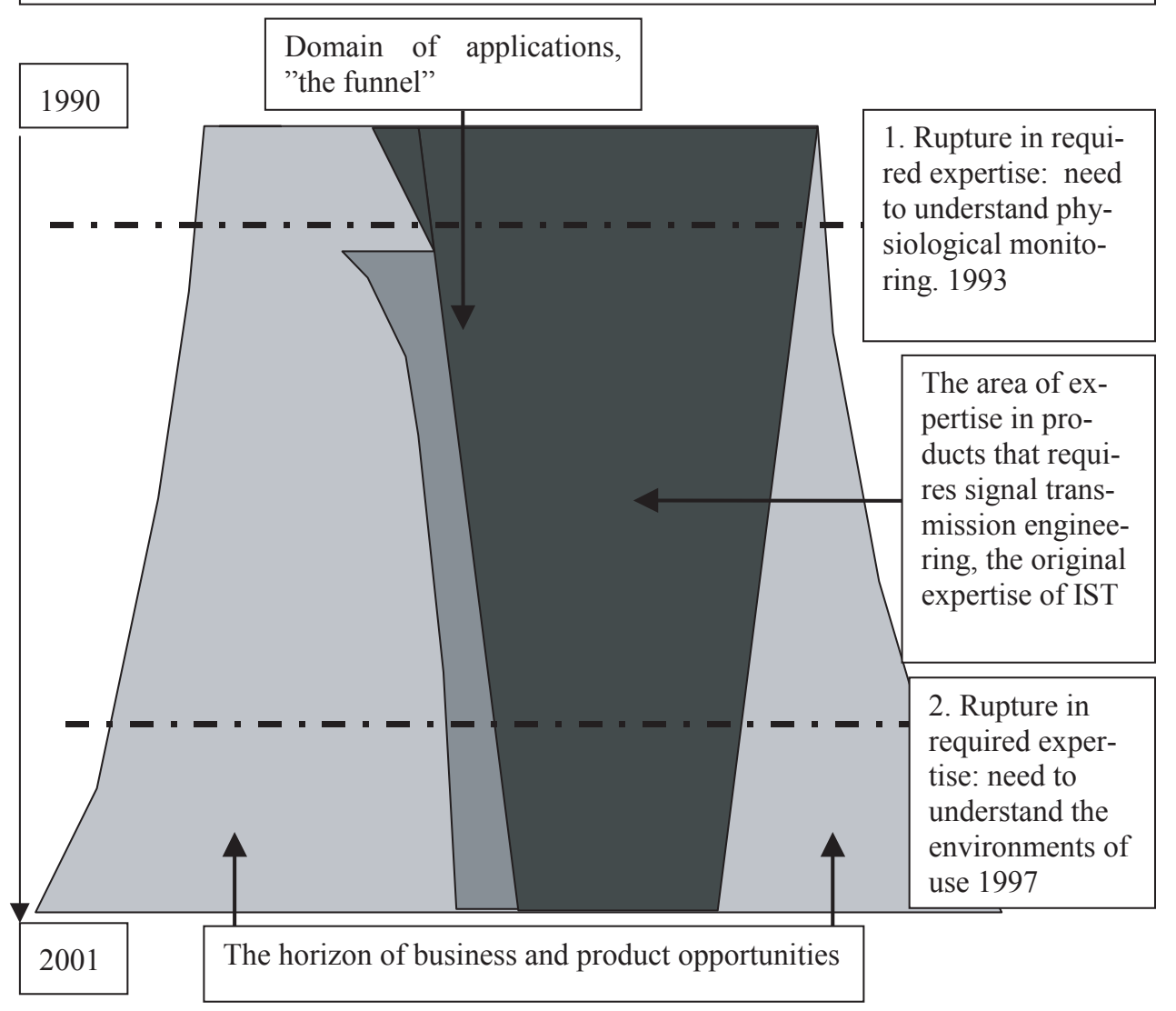

\subsection{Towards an activity theoretical interpretation of the development of $R \& D$}

The intermediary concepts provided a way to abstract some key developments from the complexity of the product development. The intermediary analysis can be interpreted in activity theoretical terms by connecting with the changes that occurred in the subjects, ob- jects, mediational means, community and collective motive. On the one hand, the changes in the application domain and in the horizon of possible future products were changes in the object(s) of activity. On the other hand, this change was connected to the expertise and, thus, to the material and conceptual means of the developers as well as to the changes in the work community. Continuities in the systemic changes of these el- 
ements provide clues to how the underlying collective motive changed during the process. $^{7}$

The work in the Nokia-Sostel period is characterized best as using and extending the engineering expertise of the members to various technical problems of signal transmission, creating new products as applications of their expertise and moving them towards commercialization. This professional activity was promoted in various projects in a number of different companies. The actions of the members were closely tied to their education, careers, and professional identity. The core of the acquired motive resided in their professional capability while its particular product-applications in a sense were secondary. They participated in the activity of signal transmission engineering in the area of residential security.

While pursuing the long-term practical work in a local work community of IST, the project developers' actions increasingly focussed on a particular product. Out of this, a new layer of collective motive gradually emerged in the local community of work. The engineers' expertise and self-identity were no longer restricted to signal transmission. They were increasingly preoccupied by other critical aspects for the success of their new product. These included, as mentioned, work and expertise in monitoring technologies, understanding physiological condi-

7 The object and motive of an activity cannot be directly deduced from any empirical material. The major ways to infer them are participants' retrospective and prospective accounts as well as tracing the continuities in the actions of the participants (Foot, 2002). Both these ways pose serious problems of presentation in the format of an article since they require plenty of space. I resorted to a "monological" description of actions without interview clips in this paper since the clips would have to be highly selective. Such a selection would leave less room for the reader to question my analysis than an equally long description of the process does (cf. the argumentation in Foot's article relying on data-exerpts with her more concise analysis in her dissertation (Foot, 1999, 2002). tions, user-interface design and understanding of users' work.

Here I see the rise of a new (local) system of activity that began to have obduracy around 1998-1999. While some aspects of this emerging activity naturally resemble those prevailing in the industry, ${ }^{8}$ it also has some particular characteristics. The participants had a widely shared imaginary and a sense of reason for doing the job. They all reported that they believed that this technology will "make it big", and they wanted to be part of the project of making it so. Several participants explicated that they saw Wristcare as their first truly special change, or, the last one before retirement (interview rounds with the whole personnel, 1999, 2000). They identified themselves with the technology explicitly as well as implicitly. None of them pointed out any other interest for their participation than business and engineering. The care of the elderly was seen as a field of business. These motivational dynamics highlight the importance of the connections between the transformation of the products and expertise. These changes are part of important transitions in the whole community of practice. In the following I shall draw further implications from these findings.

8 The community had a certain working style of regular and heroically long after-hours efforts. It had a settled division of labor by primary expertise and projects but blurred responsibilities because of frequent re-assignments to the most urgent projects and of "firefighting" that ranging from bug-fixing in user sites to joint efforts in a production series. All these may be regarded as typical of small high-tech companies seeking rapid growth. 


\section{Considerations for practice and theory}

\subsection{Explanations for practical con- cerns: to create expertise and identity takes time}

The above elaborations have put us in a position to shed more light on the questions I raised at the end of section 3. The first question was why the development process of Wristcare has taken 10 years from having the idea to a state where the product can be called an innovation, that is, be recognized as a novelty that is important in the sense of being practically useful (Miettinen, 1996). In practice this means a stage where users regard the product as working and useful and where the product has established a market that has begun to make the cost-benefit ratio brake even. Research supports the accepted wisdom that genuinely innovative products take plenty of time (10 years not yet being particularly long), precisely because of the unexpected hindrances and the time it takes to prepare the product for being genuinely useful (cf. Miettinen, Lehenkari et al., 1999; Van de Ven, 1999; Hasu, 2001). However, it has also been claimed that the development cycles have intensified and the development times radically shortened in the IT-industry (cf. Ulrich and Eppinger, 1995).

The above analysis allows us to specify some of the reasons and dynamics that have slowed the research and development process for Wristcare. When we look at the development of expertise, we notice that there have been two ruptures and additions to the original expertise of the developers, namely knowledge of physical monitoring and understanding of user-environments. Lack of funds prevented IST from acquiring this competence from the outside. Only in the beginning could it afford to buy some of the monitoring expertise from external consultancies: VTT, marketing analysis from SAI and HUT, and a design project from Uiah (see Hyysalo, forthcoming, for more details). Likewise, only after the company growth in 2000 could it hire people with a background in medical engineering.

Even with improved funding, the learning challenge would have been considerable and time consuming. Learning about physical monitoring and the user-environments was not just about learning facts, know-how and skills about these domains, but also learning about the contexts, e.g., the norms, values and standards of physical monitoring associated with the medical profession. In the terminology of Gregory Bateson's well known taxonomy, the learning challenge was not only restricted to first order learning, but it was significantly about second order learning (Bateson, 2000, 279-309). Finally, the efforts at second order learning had to do with change in the collective motive and the developers work identity: The learning necessary to master the new areas of expertise under severe time pressures contradicted the attempts to maintain the previous expertise. This also leads us to an answer of the second question on why a more user-centered product design took so long to be established? It not only required will and skill, but time, effort and organizing while resources for establishing them were constantly challenged and de-prioritized by all other projects the company was struggling with. The increase in personnel, the clarified division of labour, and the scheduling of $\mathrm{R} \& \mathrm{D}$ projects since 2001 have become a potential ground for more focused and explicit efforts.

The preceeding analysis also gives some explanation of the difficulties in accomplishing a secure and reliable monitoring, an issue IST intended to have solved by 1996. It is evident that there was a gap between the originally expected expertise and what was 
actually required to make the devices work. This "gap", in other words what the continuing transformation of the object required from the subjects, also marks the extent to which exploring and learning had to occur during the innovation process in order to fill the gap. The changes in the initial and later understandings of what is involved in constructing the device, created an internal contradiction between the early solutions, already materialized in the artifact, and the currently desired solutions. A similar dynamics prevailed along with other aspects of the organizational transformation in 2001. While a number of different projects and unpredictable "fire-fighting" actions demanded time from one another in a very tense manner, the engineers at IST managed to create a way of coping with all the pressure and complexity. Even though they viewed it as a crazy way of doing things, it had become the way in which the emerging local system of activity had worked and the manner in which the engineers could manage to deal with the multiplicity of complex objects in the many simultaneous projects. The organizational transformation re-shuffled expertise and responsibilities, and, as with any new attempt, produced for a start poorer results for coping with the tense situation in the product development. As Bateson pointed out, even an attempt to resolve contradictory demands between two or more conflicting second level learning contexts by changing the construction of the character of the learner is potentially dangerous for the integrity of the subject. He termed this Learning 3 and saw it as a rare phenomenon in human individuals, but did not address the question about transformation of collectives. According to my above analysis, the community of practitioners related to IST had gone through one major motive transformation that allowed them to continue to act and make sense of the contradictory demands and standards in the do- mains of expertise they came to operate in. The re-organization again questioned the structures created for this task and, thus, contributed to ambivalence in regard to new and old ways of organizing the R \& D in IST.

\subsection{The concepts of object and motive revisited}

In section 1, I outlined a strategy of analysis that would allow the initial meta-theoretical concepts to be reflected in light of the empirical analysis. Since the data and the metatheoretical concepts of motive and object both can be interpreted in various ways, this reflection should address the relation between the initial concepts, their interpretations in other related cases, and the data analysis presented here. In section 2, I introduced Leontjev's model of activity in which the motive corresponds with the object of activity. Both are referred to in the singular, meaning that they form a complex in which the collective motive animates the transformation of the joint object towards outcomes. Empirical studies in activity theory on science and technology show that both the object and the motive turn out to involve a complex combination of different elements (Christiansen, 1996; Engeström and Escalante, 1996; Holland and Reeves, 1996; Miettinen, 1998; Hasu, 2001; Saari and Miettinen, 2001; Foot, 2002; Saari, forthcoming). This has resulted in different ways of using the established concepts as well as new concepts, and at least a seeming confusion over the relations between them. To clarify, rather than add to the confusion, I start with Leontjev's "orthodox" model and work through its major implications and modifications, first in regard to the concept of object and then in regard to the concept of motive.

When the object of activity is understood in the singular, the specific objects trans- 
formed in the activity, in fact, become subordinate objects at the level of actions (i.e., objects of temporally and spatially limited goals) which are arched over and integrated by the overall object of the collective activity. As I outlined in section 2, this schematic model leaves the impression that the relations between the subordinate objects and the overarching object are distant, as the overarching object is highly stable and consistent while the subordinate objects are transitory and spatio-temporally limited. Intuitively, such a scheme proposes that subordinate objects have little impact on the overall object, or that such an effect has to be highly mediated. To enable more sensitivity to changes in the overall object of activity, I initially adopted the model that Miettinen and Saari developed in their studies of scientific research. They propose that the specific objects transformed in the activity are organized as "application objects", i.e. intermediary wholes spanning significant time periods and collective efforts (Miettinen, 1998; Saari and Miettinen, 2001; Saari, forthcoming). Resistance in the realization of application objects may then also question and re-shape the overall object of the activity. The case of the IST product development supports this kind of view of objects in a rapidly changing product development work. The efforts in IST were organized around fairly long-standing projects which were relatively independent and had indefinite end-point. Their success and the problems they faced had a significant impact on the shape of the overall activity. The metaphor of application, on the other hand, assumes the existence of a core expertise that is then applied to particular cases. I would rather refrain from this kind of assumption about a primacy between the objects and call the intermediary, integrative wholes "project objects" since that is also a more applicable term in fields other than science.
The idea about project objects entails that we must raise the question whether a collective, integrative object was accomplished in the activity under study. In this respect the object resembles the notion of an expansive learning cycle Engeström introduced in late 1980 's. Built into this notion is the developmental potential of expansion which is a valuable insight. However, as most people familiar with Engeström's work will know, he constantly questions and warns against assuming expansion when the cycles might also be stationary, decreasing or dispersing. The notion of an integrative object is similarly laden with the potential to expand (Engeström, 1987). The very possibility of expansion conveys that a full integration of subordinate objects has not always - or in a strict interpretation ever - fully taken place. This is also highlighted in the empirical studies on the expansion of objects (e.g., Hasu, 2001). The skepticism against the assumption of finding an overarching object may also be backed by other disciplines in studies of technology. Callon pointed out that in the production of technology the social formations, or actor-networks as he calls them, range from ill-defined and fluctuating to stabilized and calculable with well-formed objectives (Callon, 1991). The integration and stability of social formations should rather be treated as an accomplishment than a theoretical presupposition (Latour, 1987; Suchman, 1987; Callon, 1991; Latour, 1991; Bijker and Law, 1992; Bijker, 1995). It would be a mistake to analyze an emerging collective in terms presuming that it is highly stabilized, in other words, caution should be exercised when inferring the presence of an over-arching object from e.g. number of project objects.

This discussion can be taken even further with the concept of motive. If, as Leontjev posits, the collective motive of an activity is 
presumed to be singular, the various forms of heterogeneity and multi-voicedness are seen to reside either 1) "below" the collective motive at the level of individual goals and actions, for example, as interpretations or "perspectives" of individuals or subgroups on the motive (Holland and Reeves, 1996; Foot, 2002), 2) as strands within the collective motive (Saari and Miettinen, 2001; Saari, forthcoming), 3) as contradictions within the object carrying the motive (Engeström, 1990a, 93), or 4) in between activities as in analyses of network collaboration (Miettinen, 1998; Lehenkari, 2001).

My case study provides grounds to question whether these are the only alternatives. As we recall, there was a shift in the motives of the IST from a professional motive to a more locally specified one. Based on the assumption of a singular collective motive, one might propose three "archetypical" interpretations of this shift: A) There were two motives and, correspondingly, two activities with a transitional period between them. B) We saw the emergence of a local activity in which previously independent goals were integrated around 1998. Or, c) the motive and object of the activity integrated both the professional and the local motivational strands all along, but went through a radical reformulation and change in their respective emphasis during the process. I find each of these interpretations problematic as descriptions of change. Interpretation b) treats the early years of the company as if they took place in a vacuum of a collective motive, covered only by an "empty shell" and leaving the analyst with an all-or-nothing option: either there is a fully integrated whole or an empty "shell covering the individual goals of its participants" (Foot, 2002, 33). Interpretation a) gives a blunt view of change and continuity: motive 1 , no motive 2 à intermediary period à motive 2 , no motive 1 . In this respect interpretation $\mathrm{c}$ ) is more sound since it is obvious that, e.g., the strand of professional motive/goal will hardly ever vanish from the activity. The problem with interpretation c) is that it does not elaborate how motive 2 emerged from motive 1 because it assumes these strands were integrated all along within a single, motivational whole. An elaboration of c), or even an alternative explanation, may be reached by abandoning the assumption of a correlation between one collective motive and activity and interpreting that the emergence of the local activity brought about a situation where two collective motives continued to animate an activity without (at least so far) being integrated (cf. Foot, 2002, 33). Whether they should be treated as facets of the same motive or as copresent separate motives is then left to the empirical materials.

In the IST case, a separation between the two motives is called for by their qualitative difference in the structurally different types of activity they animate. The emerging local motive unifies multiple domains of expertise in a single, local community organized around a particular new technology. The previously dominating professional motive is restricted to a single professional field and yet was radically more trans-local since it animates actions in numerous different companies and institutions and is relatively independent of any single set of projects or applications. Such qualitative differences in motives and activities are by no means a novel finding. There seems to be variations among activity theory scholars in what constitutes an activity and its motive ranging from, e.g., Leontjev's model in section 2 to his passing remarks on the activity and motive of an individual (Leontjev, 1978), onwards to motives of historically formed, local activity systems (Engeström, 1987) to, e.g., professional motives (Chaiklin, Hedegaard et al., 1999). Rather than engaging in a scholastic debate about what "the" right in- 
terpretation is, I prefer to question whether these differences reflect something real and vital in the reality analyzed.

Already Leontjev noted that an action may simultaneously serve multiple motives (Kaptelinin 1996, 58). He also saw that a personality develops as a result of participating in a number of activities during one's life (Leontjev, 1978; cf. Valsiner, 1998). The theme of "polymotivation" is, thus, a central issue in understanding the determination and formation of action and subjects. As activity theory has moved from a psychologically oriented study of individuals to collective agents (Kaptelinin, 1996, 57), a viable question becomes whether collective activities should be assumed and analyzed as monomotivated or whether it would make sense to address their motives as a complex of separate strands.

Potential conceptual benefits from regarding an activity as poly-motivated may be highlighted with the Miettinen's concept of a dual object that I introduced in sections 2.2 and 5.2. Miettinen characterizes scientific objects as epistemic objects from the point of view of a scientific interest and as having a certain use-value as outcomes for non-scientific venues. While it is clear that scientific objects do carry such dual meanings, conceptual linking use-value only with non-scientific venues (non-scientific activities) may conflate issues somewhat misleadingly because it attributes dimensions to objects with corresponding activities. The idea of polymotivation might be used to re-conceptualize that scientific objects and actions should instantiate two different collective motives both present in scientific work. The first motive has to do with the development of expertise, the intricasy of the objects studied, and the vages and prestige gathered in scientific practice. The second motive has to do with the application of the results in other societal practices. Both these motives have a use-value as well as an exchange value dimension, and neither of them has a monopoly on the epistemic interest in the objects under transformation. The use-values, exchange values and the epistemic interest are, however, likely to be radically different in the two venues. But while both conceptualizations say essentially the same about the empirical findings, the two-motives-one-activity-model avoids the misleading attribution of epistemic and use-value dimensions to separate activities (or at least to separate dimensions of the same activity).

\section{Conclusions}

The aim of this paper was to explore how an activity theoretical orientation and especially the concepts of object and motive would inform the analysis of a long-standing product design effort. The major benefits from activity theory consisted in enabling a systemic analysis that could integrate the contingent incidents with more continuous lines of transformation stemming from both the objects and the subjects. This helped to clarify the structure of the learning challenges involved in the Wristcare innovation process. The case-analysis could also be used to reflect back on the meta-theoretical concepts and their interpretations in empirical studies. The IST case study argues for a greater sensitivity to the nature of motives and objects in activities. The ability to address the wider context and continuities beyond the transient actions is one of the strong points of activity theory. However, work such as product design or scientific research feature rapid changes in the objects, in projects as well as in the social organization of activity. Intermediary concepts between activity and action such as "project objects" and "strand of motive" may prove useful in accounting for the less-than activity level continuities and for the dynamics of change in such less-sta- 
bilized activities. In a similar vein, the "polymotivation" and inter-animation of heterogeneous imaginaries in action and collective activities should be considered as an analytical possibility.

\section{Acknowledgements}

If activity theory is suitably characterized as a "well kept secret", the object of activity must be its sacred ground, difficult to learn and have an informed opinion about. I would like to thank Reijo Miettinen for his encouragement with the numerous earlier versions of this paper, Jussi Silvonen for his guided tours to the scholastics of cultural-historical psychology, Kirsten Foot for her help with clarifying problems in the final phrasing and argumentation, and Seth Chaiklin, Yrjö Engeström, Victor Kaptelinin, Merja Helle, Janne Lehenkari, Erika Mattila, Matt Ratto, Eveliina Saari and Juha Tuunainen and the reviewers and editors of Outlines for their valuable comments to drafts and ideas. Had I followed all your advice, the paper would be just amazing..., but never finished.

\section{References}

Ankersmit, F. R. and H. Kellner (1995). A new philosophy of history. Chicago: University of Chicago Press.

Bateson, G. (2000). Steps to an ecology of mind: Collected essays in anthropology, psychiatry, evolution, and epistemology. 2nd Edition, Jason Aronson, Inc.

Bazerman, C. (1998). Languages of Edisons Light. Cambridge, MA: MIT Press.

Beiser, F. (1999). The context and problematic of post-Kantian philosophy. A companion to continental philosophy. Chritchley and Scröder: 21-35.

Bijker, W. E. (1995). Of bicycles, bakelites, and bulbs: toward a theory of sociotechnical change. Cambridge, Mass.: The MIT Press
Bijker, W. E. and J. Law, Eds. (1992). Shaping Technology - Building Society: Studies in Sociotechnical Change. Cambridge, Mass.: The MIT Press.

Callon, M. (1991). Techno-economic networks and irreversibility. A Sociology of monsters: essays on power, technology, and domination. J. Law, Ed.. London: Routledge, 132-165.

Carlisle, Y. and A. Dean (1999). "Design as Knowledge Integration Capability." Creativity and innovation management 8(2): 112-121.

Chaiklin, S. E., M. Hedegaard, et al., Eds. (1999). Activity theory and social practice. Aarhus: Aarhus University Press.

Christiansen, E. (1996). Tamed by a Rose: Computers as Tools in Human Activity. Context and Consciousness. Activity Theory and Human Computer interaction. B. Nardi, Ed. Cambridge, MA: The MIT Press, 147-175.

Engeström, R. (1995). "Voice as communicative action." Mind, Culture, and Activity 2(3): 192-215.

Engeström, Y. (1987). Learning by Expanding. Helsinki: Orienta-Konsultit.

Engeström, Y. (1990a). Developmental work research as activity theory in practice: analyzing the work of general practitioners. Learning, Working, Imagining. Twelve Studies in Activity Theory. Helsinki: Orienta Consulting: 69-107.

Engeström, Y. (1990b). Constructing the Object in the Work Activity of Primary Care Physicians. Learning, Working, Imagining. Twelve Studies in Activity Theory. Helsinki: Orienta Consulting: 107-130.

Engeström, Y. (2000). "Activity theory as a framework for analyzing and redesigning work." Ergonomics 43(7): 960-974.

Engeström, Y. and V. Escalante (1996). Mundane Tool or Object of Affection? The Rise and Fall of the Postal Buddy. Context and Consciousness. Activity Theory and Human Computer Interaction. B. Nardi. Ed. Cambridge, MA: The MIT Press: 325-374.

Engeström, Y., R. Miettinen, et al. (1999). Perspectives on activity theory. New York: Cambridge University Press. 
Fleck, J. (1994). "Learning by Trying: The implementation of configurational technology." Research Policy 23: 637-652.

Foot, K. (1999). Writing conflicts: an activity theory analysis of the development of the Network for Ethnological Monitoring and Early Warning. Academic Dissertation, Department of Communication, University of Califormia San Diego.

Foot, K. (2002). "Catching an Evolving Object." Mind, Culture, and Activity. Forthcoming.

Gadamer, H. G. (1975). Truth and method. New York: Seabury Press.

Geertz, C. (1973). The interpretation of cultures; selected essays. New York: Basic Books.

Hasu, M. (2001). Critical Transition From Developers to Users. Department of Education. University of Helsinki.

Hegel, G., Friedrich, Willhelm (1970). Phenomenology of spirit (Phänomenologie des Geistes) 1807. Frankfurt/Main: Suhrkamp Verlag.

Holland, D. and J. R. Reeves (1996). Activity Theory and a View from Somewhere: Team Perspectives on the Intellectual Work of Programming. Context and Consciousness. Activity Theory and Human Computer interaction. B. Nardi. Ed. Cambridge, MA: The MIT Press: 257-282.

Houlgate, S. (1999). Hegel. A companion to continental philosophy. Chritchley and Scröder: 93-107.

Hughes, T. (1983). Networks of Power: Electrification in Western Society 1880-1930. Baltimore: John Hopkins University Press.

Hyysalo, S. (forthcoming,a). "Users, an emerging human resource for R\&D? From preference elicitation towards the joint exploration of users' needs." Submitted to International Journal of Human Resource Development and Management.

Hyysalo, S (forthcoming,b). Representations of use, technological frames and practice bound imaginaries in automating the safety of the elderly.

Ilyenkow, E. V. (1977). The Problem of the Ideal. Philosophy in USSR: Problems of Dialectical Materialism. Moscow: Progress.
Kaptelinin, V. (1996). Computer-Mediated Activity: Functional Organs in Social and Developmental Contexts. Context and Consciousness. Activity Theory and Human Computer interaction. B. Nardi. Ed. Cambridge, MA: The MIT Press: 45-67.

Kozulin, A. (1990). Vygotsky's Psychology. New York: Harvester Wheatsheaf.

Latour, B. (1987). Science in action: how to follow scientists and engineers through society. Cambridge, Mass.: Harvard University Press.

Latour, B. (1991). Technology is Society Made Durable. A Sociology of monsters: essays on power, technology, and domination. J. Law. Ed. London: Routledge: 103-132.

Law, J. Ed. (1991). A Sociology of monsters : essays on power, technology, and domination. London: Routledge.

Lehenkari, J. (2001). Studying Innovation Trajectories and Networks: The Case of Benecol Margarine. Science Studies, 2000. 13(1): p. 50-67.

Leonard-Barton, D. (1995). Wellsprings of knowledge: building and sustaining the sources of innovation. Boston, Mass.: Harvard Business School Press.

Leontjev, A. N. (1978). Activity, Consciousness, and Personality. Moscow: Progress.

Leontjev, A. N. (1981). Problems of development of mind. Moscow: Progress.

Marx, K. (1984). Theses on Feuerbach. K. Marx \& F. Engels: Basic Writings on Politics and Philosophy. L. S. Feuer, Fontana.

Marx, K. and F. Engels (1959). Economic and philosophic manuscripts of 1844. Moscow: Foreign Languages Publishing House.

Miettinen, R. (1996). "Theories of invention and an industrial innovation." Science Studies 9(2): 34-48.

Miettinen, R. (1998). “Object Construction and Networks in Research Work: The Case of Research on Cellulose Degrading Enzymes." Social Studies of Science 28. p. 423-463.

Miettinen, R., J. Lehenkari, et al. (1999). Osaaminen ja uuden luominen innovaatioverkoissa. Helsinki: Taloustieto. 
Mutanen, U.-M. (2002). From New Products to New Practices: An Activity Theoretical Perspective to the Transformation of Product Development Work. ISCRAT, Amsterdam.

Nardi, B. A. Ed. (1996). Context and consciousness: activity theory and human-computer interaction. Cambridge, Mass.: MIT Press.

Norros, L. (forthcoming). Acting under Uncertainty. The core-task analysis in naturalistic study of work and expertise.

Prahaland, C. K. and G. Hamel (1990). The Core Competence of the Corporation. Boston: Harvard Business School Press.

Rip, A., T. J. Misa, et al. (1995). Managing technology in society: the approach of construc tive technology assessment. London: Pinter Publishers. Distributed in the United States by St. Martin's Press.

Saari, E. (forthcoming). The Pulse of Change in Research Work. Department of Education. Helsinki: University of Helsinki.

Saari, E. and R. Miettinen (2001). "Dynamics of change in Research Work: Constructing a New Research Area in a Research Group." Science, Technology, and Human Values 26(3): 300-321.

Schon, D. (1983). The Reflective Practitioner: How Professionals Think in Action. New York: Basic Books.
Silvonen, J. (1988). Kriittisen subjektitieteen luonnos. Klaus Holzkampin Grundlegung der Psychologien tarkastelu. Joensuun yliopisto.

Simon, H. A. (1996). The sciences of the artificial. Cambridge, Mass.: MIT Press.

Suchman, L. (1987). Plans and Situated Actions: The Problem of Human-Machine Communication. Cambridge: Cambridge University Press.

Ulrich, K. T. and S. D. Eppinger (1995). Product design and development. New York: McGraw-Hill, Inc.

Valsiner, J. (1998). The guided mind: A sociogenetic approach to personality. Cambridge: Harvard University Press.

Van de Ven, A. H. (1999). The innovation journey. New York: Oxford University Press.

Williams, R. and D. Edge (1996). "The social shaping of technology." Research policy 25 : 865-899.

Vygotsky, L. (1989). Thought and Language. Cambridge, MA: The MIT Press.

Vygotsky, L. S. (1978). Mind in Society. The Development of Higher Psychological Processes. Cambridge: Harvard University Press.

Zaff, B. e. a. (1993). "Capturing multiple perspectives: a user-centered approach to knowledge and design acquisition." Knowledge Acquisition 5: 79-116. 